\title{
Runoff sediment and $P$ losses from various soil management practices: modelling in hilly slopes
}

\author{
Paulo Roberto da Rocha Junior ${ }^{1 *}$, Rabin Bhattarai ${ }^{2}$, Raphael Bragança Alves Fernandes ${ }^{3}$, \\ Prasanta Kumar Kalita ${ }^{2}$, Felipe Vaz Andrade ${ }^{1}$
}

${ }^{1}$ Universidade Federal do Espirito Santo, Department of Plant Production, Alto Universitário, Gurarema s/n, Alegre, 29500-000, ES, Brazil. ${ }^{2}$ University of Illinois, Department of Agricultural and Biological, Engineering, 338 Agricultural Engineering Sciences Building, 1304 W. Pennsylvania Avenue, IL 61801, Urbana, Illinois, USA. ${ }^{3}$ Universidade Federal de Viçosa - Departament of Soil Science, Av. Peter Henry Rolfs s $n$, Campus Universitário, 36570-900, Viçosa, MG, Brazil.*Corresponding author: rocha.pjunior@gmail.com

\begin{abstract}
This study aimed to evaluate the effect of soil management on water, sediment and P losses in slope plots in east-central Illinois, USA. Field and laboratory experiments were conducted. The soil management studied were: tillage in contour (CT), tillage in downhill (DT), no-tillage (NT) and bare soil (BS). After collecting the field data, WEPP model was used to model the erosion process. The NT and BS management resulted in low (152.35 mm field; $28.51 \mathrm{~mm}$ laboratory) and high (315.25 mm field; $63.67 \mathrm{~mm}$ laboratory) water loss respectively. For soil losses, similar behavior was observed for NT ( $0.45 \mathrm{t} \mathrm{ha}^{-1}$ field; $0 \mathrm{t} \mathrm{ha}^{-1}$ laboratory) and BS (87.27 $\mathrm{t} \mathrm{a}^{-1}$ field; $0.86 \mathrm{t} \mathrm{ha}^{-1}$ laboratory) managements. In case of P losses, CT management resulted in the lowest loss (216.26 $\mathrm{g} \mathrm{ha}^{-1}$ ) while high values were found in the BS management (1806.06 $\left.\mathrm{g} \mathrm{ha}^{-1}\right)$. The modeled results obtained from WEPP model did not show a good agreement with the data collected at field overestimated and underestimated the soil and water losses. The enrichment rate of runoff with sediment was influenced by soil management practices and the DT (34.48 $\left.\mathrm{g} \mathrm{L}^{-1} \mathrm{~min}^{-1}\right)$ management showed the high peak. The adoption of NT management in agriculture areas with high slope (32\%) can be beneficial to reduce erosion process. The total removal of vegetation cover leaving the soil exposed, similar to the BS management and soil preparation along the slope (DT management) should be avoided.
\end{abstract}

Key words: Conservational practices, no tillage, erosion modelling, soil erosion, WEPP model.

\section{Introduction}

Soil erosion is the main cause of soil degradation around the world, and various soil management practices have been developed to reduce the soil erosion (Wei et al., 2010). Among the soil management practices adopted among farmers in the USA, conventional tillage with plowing and 
harrowing, and conservation tillage with no-tillage stand out. However, conservational tillage is widely used since it results in the better soil conditions (Horowitz et al., 2010). It has been estimated that 88 million acres have no tillage operations in 2009 , and were managed with conservation tillage with high residue deposition in the USA (Horowitz et al., 2010). However, this scenario can change with the expansion of crops being used in energy production (Drewniak et al., 2015). A study on the management practices adapted by the farmers reported that the residues generated in the fields could be widely used for the generation of the biofuel and ethanol for meeting the energy and food security goals (Lynd et al., 2008). For example, maize is estimated as the source for about $40 \%$ of the agricultural biomass available for biofuel production in the USA (Perlack et al., 2005). The Renewable Fuel Standard of the US Energy Independence and Security Act (EISA, 2007) sets a national target of producing 136 billion liters of renewable fuels by 2022 (Drewniak et al., 2015). Out of 136 billion liters of renewal fuels, at least 61 billion liters is expected to come from cellulosic ethanol (Beniston et al., 2015). Although this results in the gains of energy production, the exposure of soil due to the use of the residues for energy purpose can cause the increase of sediment, water and nutrients loss, especially $\mathrm{P}$ that is essential for plants growth and major problems to water bodies eutrophication (Jarvie et al., 2013).

Over the last decades, many researchers have studied the sediment and water losses in different soil management, and several mathematical models have been developed to estimate the erosion process in these managements (Flaganan et al., 1995; Arnold et al., 1998). A helpful tool that has been widely used in order to study the erosion process in different soil management is the Water Erosion Predict Project
(WEPP) (Nearing et al., 1994). This model is process-based that incorporates rill and inter-rill erosion concepts and simulates the processes occurring in a particular area taking in consideration soil, vegetation, crop residues and soil moisture. The WEPP model may be a viable alternative due to being a process-based model, easy access and a good predictive ability (Flaganan et al., 1995). To our knowledge, there are only few studies where the WEPP model was calibrated and validated using data collected from different soil managements in hilly slopes (Shen et al., 2010). In this sense, new studies need to be conducted to study the effect of the managements changes such as the erosion process, transport of nutrients, and evaluate the WEPP model performance in areas with a greater slope. Studies with erosion process can reduce or mitigate the effects of possible management changes, and the calibration of WEPP using data collected in field can diminish the cost of sediment and water loss determination, allowing upscaling estimation.

In this study, we investigated different factors related to the erosion process in the various agricultural management practices on a hill slope area. The change in the amount of sediment and water losses, the relation between the amount of phosphorus (P) and the capacity of WEPP model to estimate the water and soil losses were studied.

\section{Material and Methods}

Field experiment were carried out during summer season in 2015 at the University of Illinois experimental farm in Urbana, IL. Following the field experiments, laboratory experiments were conducted under a rainfall simulator at the Agricultural and Biological Engineering Department at the University of Illinois. The details of field and laboratory experiment are provided below. 


\subsection{Field experiments}

\subsubsection{Plots preparation and soil managements}

The field experiment was conducted in the Erosion Control Research and Training Center located at Agriculture and Biological Engineering research farm in southeast Urbana-IL, USA. The most predominant soil type at the site is Mollisol clayey (USDA, 2013)
(Table 1). Four plots were utilized, one for each soil management with $10.62 \mathrm{~m}$ of ramp length, $2.64 \mathrm{~m}$ of width and $32 \%$ of slope. Metal borders surrounding the plots were inserted to a depth of $0.15 \mathrm{~m}$ to avoid overland flow losses or gains from adjacent plots. To evaluate and collect overland flow, each plot was equipped with a tank with capacity of $910 \mathrm{~L}$ at the down slope end.

Table 1. Chemical and physical characterization

\begin{tabular}{|c|c|c|c|c|}
\hline $\mathrm{pH}$ & SOC & $\mathrm{P}$ & K & $\mathrm{CEC}$ \\
\hline $\mathrm{H}_{2} \mathrm{O}$ & dag $\mathrm{kg}^{-1}$ & \multicolumn{2}{|c|}{---------'mg dm ${ }^{-3}---------$} & $\mathrm{cmol}_{\mathrm{c}} \mathrm{dm}^{-3}$ \\
\hline 6.45 & 4.00 & 26.00 & 276.50 & 12.20 \\
\hline Sand & Silt & Clay & $\mathrm{Bd}$ & Ko \\
\hline --.-- & dag $\mathrm{kg}^{-1}$ & $\cdots$ & $\mathrm{g} \mathrm{cm}^{-3}$ & $\mathrm{~cm} \mathrm{~h}^{-1}$ \\
\hline 11 & 14 & 75 & 1.50 & 3.30 \\
\hline
\end{tabular}

SOC: Soil Organic Carbon; CEC: Cation Exchange Capacity; Bd: Bulk Density; Ko: Hydraulic conductivity.

Four different soil management were evaluated during this experiment. Contour tillage (CT) was implemented by tilling the soil in the contrary sense of the hill adopting a depth of $15 \mathrm{~cm}$. One day after the soil tillage, fertilizer was applied on the surface corresponding to 50 $\mathrm{kg} \mathrm{N}, 30 \mathrm{~kg} \mathrm{~K}$ and $110 \mathrm{~kg}$ P per ha ${ }^{-1}$. Similar fertilization practice was used for the others soil managements. Downhill tillage (DT) was implemented tilling the soil following the direction of the slope to a depth of $15 \mathrm{~cm}$.
No-tillage (NT) management was implemented using equivalent $24 \mathrm{t} \mathrm{ha}^{-1}$ of oat straw under cover (Downing et al., 2011). Bare soil (BS) plot was used as the control with no soil management with periodic weed removal in order to eliminate all possible weeds. Except to the bare soil management, all management were manually planted seeds of Kentucky blue grass (Poa pratensis) that were buried in the soil with a rate of $30 \mathrm{~kg} \mathrm{ha}^{-1}$, which was used as cover crop (Figure 1). 
(a)

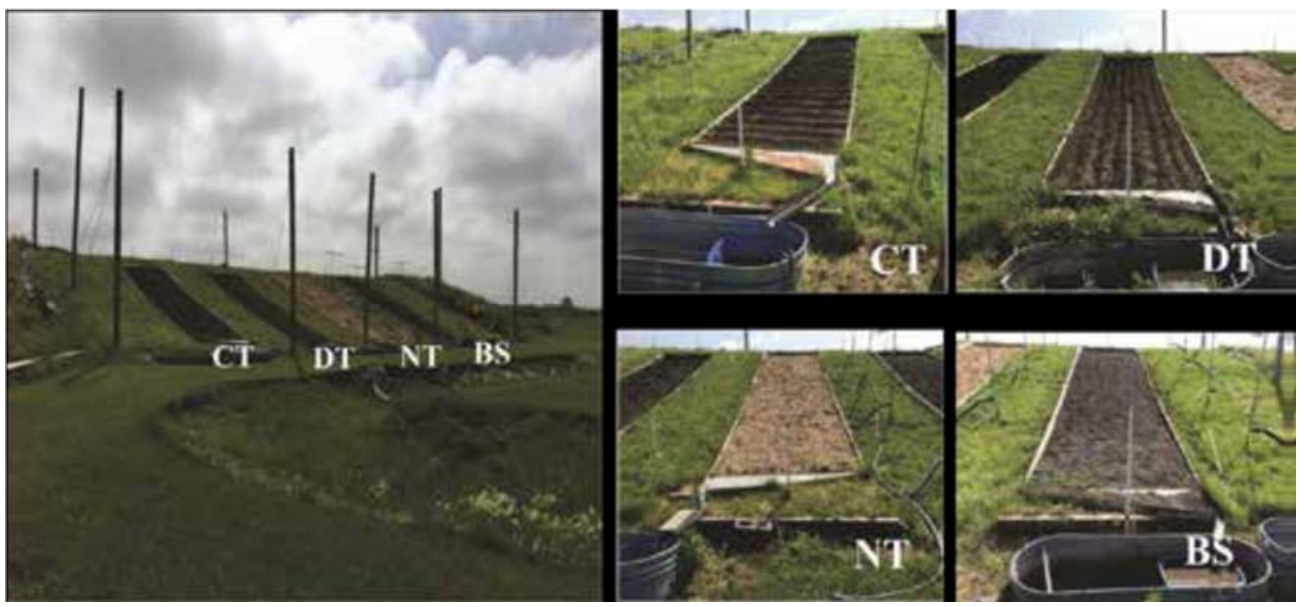

(b)

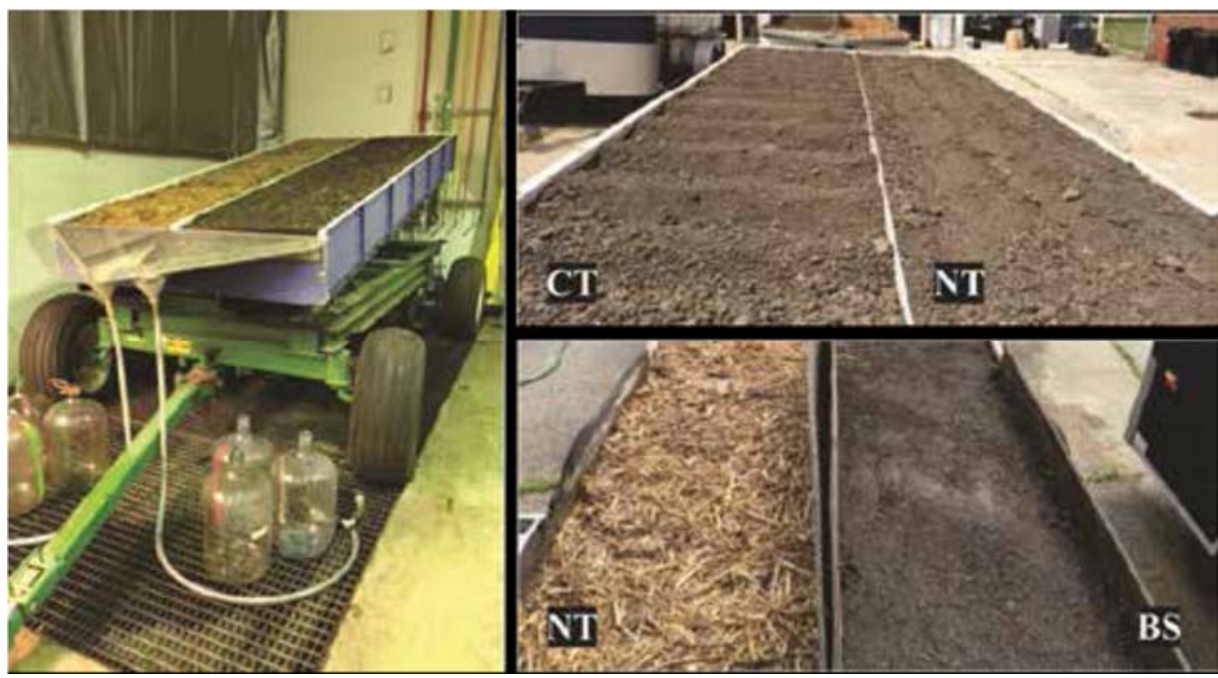

Figure 1. Field plots studied (a) and laboratory plots studied (b). CT-Contour tillage; DT- Downhill tillage; NT- No tillage; BS- Bare soil. 


\subsubsection{Data collection}

The loss of water was measured after each rainfall event using graduated buckets to measure the amount of water lost, and the water samples were collected for analysis of P. For determining the loss of sediment, all remaining material in the gutters and supernatants inside the boxes were collected. The sediment was air dried and weighed. Water samples were filtered $(0.7 \mu \mathrm{m})$, and were analyzed to determine P contents by colorimetric method using automated ascorbic acid reduction. Sediment samples of $0.5 \mathrm{~g}$ were digested using a mixture of concentrated sulfuric acid $(4 \mathrm{~mL})$ and hydrogen peroxide $(50 \%)$ (10 mL) (USEPA 365.21971$)$, and the contents of $P$ were determined by colorimetric method using automated ascorbic acid reduction.

2.1.3. Modeling sediment and water losses by WEPP

In order to model the sediment and water losses at the field experiment, the Water Erosion Predict Project (WEPP) (Nearing et al., 1994) program was used. Input data for the model such as climate, length and steepness of slope, soil and management were collected during the field experiment. Climate data were collected with a weather station located in the experimental farm near the experimental site. Isolated rain was studied using the function single storms, added data of storm amount (mm), storm duration (h), maximum intensity $\left(\mathrm{mm} \mathrm{h}^{-1}\right)$ and duration to peak intensity (\%). Lengths (m) and ramp slopes (\%) were taken from the section plots preparation and soil managements.

The input data regarding the soil used was from Table 1 , and as the values of interrill erodibility, rill erodibility and critical shear was not available, these variables were calculated on base of soil physical attributes, using the "have model calculate" tool. For the initial saturation level, $70 \%$ of initial level saturation, which is about $33 \mathrm{kPa}$ (field capacity) for most soils was used ase per recommended for WEPP program. Other input information collected during the experiments were bulk density after the last tillage $\left(1.1 \mathrm{~g} \mathrm{~cm}^{-3}\right)$, initial canopy cover $(0 \%)$, days after the last tillage (200 d), cumulative rainfall since last tillage (500.1 $\mathrm{mm})$, initial ridge height after last tillage $(2 \mathrm{~cm})$, and initial roughness after last tillage $(2 \mathrm{~cm})$.

\subsection{Laboratory experiments}

2.2.1. Soil chambers preparation and soil managements

The lab experiment was conducted under a rainfall simulator at the Agricultural and Biological Engineering Department at the University of Illinois. Two horizontal tilting soil chambers were used to investigate soil erosion patterns from soil under different managements. The chambers contained $3.60 \mathrm{~m}$ of ramp length and $1.50 \mathrm{~m}$ of width. The chambers were filled with similar soil to the field experiment; the unique difference was the SOC content (2.5\%). More details about the soil chamber and soil accommodation see Bhattarai et al. (2011) (Table 1).

The managements of soil adopted in lab experiment, were similar to management describe in the field experiment. The difference between lab experiment was the tillage of soil, which this procedure was done manually with a hoe. Fertilization and seed input followed the same rate adopted in field. Fertilizer was applied on the surface in all management with a rate of $50 \mathrm{~kg} \mathrm{~N}, 30 \mathrm{~kg} \mathrm{~K}$ and $110 \mathrm{~kg}$ P per ha ${ }^{-1}$. Kentucky blue grass were buried in the soil with a rate of $30 \mathrm{~kg}$ $\mathrm{ha}^{-1}$ were planted except to the bare soil management. To grow the grass the wagons were placed horizontally outside the laboratory. After 50 days when the grass reach $20 \mathrm{~cm}$ the wagons were placed inside the laboratory to simulate the rains (Figure 2). 

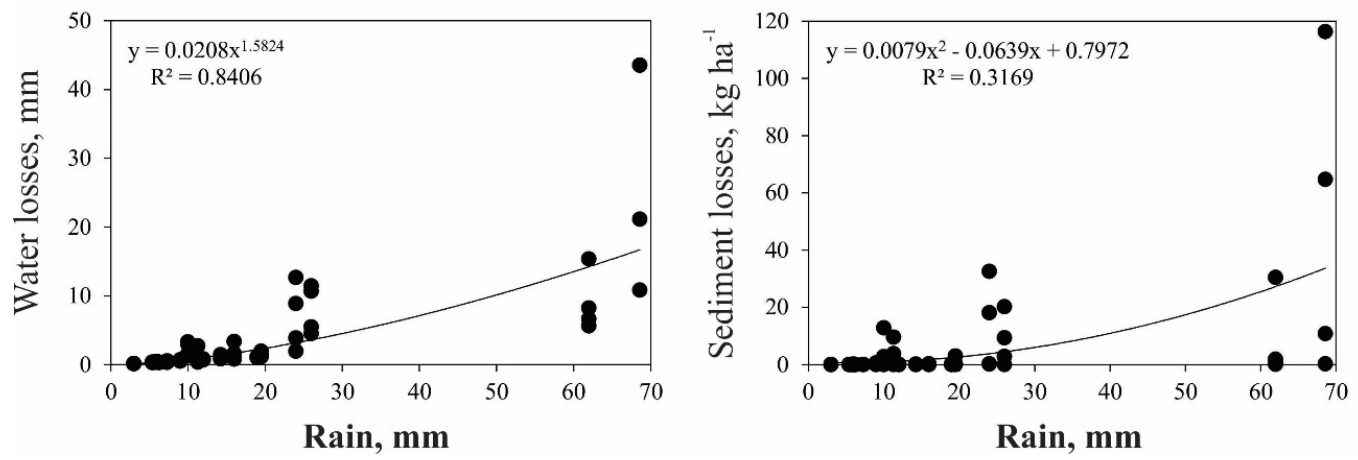

Figure 2. Relationships between rainfall event amount and runoff water and sediment in different soil managemets $(\mathrm{n}=72)$. *Significant differences at $p \leq 0.05$ using $F$-test and ANOVA.

\subsubsection{Data collection}

Two rainfall intensities were adopted: $50.3 \mathrm{~mm} \mathrm{~h}^{-1}(2$ in $\mathrm{h}^{-1}$ ) and $114.13 \mathrm{~mm} \mathrm{~h}^{-1}\left(4.5 \mathrm{in} \mathrm{h}^{-1}\right)$ for 30 minutes, which represents respectively, 1 and 50-year, of 30 minutes rainfall event in Central Illinois. The rainfall simulator consisted of two modules, $1.3 \mathrm{~m}$ apart, each containing five Spraying Systems (Wheaton, IL) Veejet 80100 nozzles that operate at $41 \mathrm{kPa}$ (Bhattarai et al., 2011). The rainfall simulator modules are located $10 \mathrm{~m}$ from the floor, this is because in this altitude majority of the drops attain terminal velocity by the time they hit the floor, thus simulating near-natural rainfall events. Since two different wagons were used in the study, it was assured that the wagon was placed at ex actly the similar position before each rain as recommended to Bhattarai et al. (2011). This was adopted in order to minimize the variation of rainfall across the plots and between the runs. We ensured also, maintain the similar soil moisture $(30 \pm 5 \%)$ in each soil management before the simulate rain, avoiding the interference of the water content in soil.

The laboratory experiments were carried out with a slope to $17 \%$, which is the maximum slope to the soil chamber. The runoff from each compartment was collected in large bottles with $23 \mathrm{~L}$ capacity. To calculate the enrichment rate of sediment in runoff, seven representative runoff samples for each soil management were collected during the runoff time for each simulated rainfall event. The samples were collected at various time stamps after the initiation of runoff (time $0,1,2,3,4,5$ and 6 ). In the final of experiment (after each event of simulated rainfall) to determine the amount of sediment, five sub samples were collected. The $25 \mathrm{ml}$ aliquot samples were placed in the oven for $48 \mathrm{~h}$ until all the water was evaporated. The total amount of sediments and water losses were converted to kilogram of sediments per hectare, and $\mathrm{mm}$ of water. 


\subsubsection{Statistical analysis}

For statistical analyses, SISVAR software (Ferreira, 2011) was used. For the field experimental data, the loss of sediment and water were correlated with the amount of precipitation using regression equation. Sediment, water and P losses collected under natural rainfall were analyzed to compute descriptive statistics such as mean, maximum, minimum, standard deviation and total accumulated for each soil management. The difference of losses between soil managements were analyzed using $F$-test and ANOVA ( $p \leq$ $0.05)$. The randomized experimental design was adopted, using as repetitions each collection carried out after each rain event $(n=18)$.

To calibrate the WEPP model, soil losses measured in the field were compared with the values of soil losses estimated by the model. To test the model results, statistical parameters as root mean square error (RMSE) and percent bias (PBIAS) were used. To the laboratory experiment water and sediment losses under each soilmanagement obtained with simulated rainfall were presented in absolute values. Enrichment rates with sedi- ment in runoff were calculated, and the enrichment rate was described using regression.

\section{Results}

\subsection{Field experiment}

Figure 3 shows the relationship between the amount of rainfall and water and sediment loss. It was observed that water loss was related to precipitation amount $\left(\mathrm{R}^{2}\right.$ $=0.84$ ), independent of soil management. However, the highest peaks were observed after the rainfall events with high volume. Same trend was found for the sediment losses. However, the relationship between these two variables (sediment and rainfall) was very low $\left(R^{2}=0.31\right)$, suggesting that other variables could be involved in the process. For sediment loss the high amount of rainfall leads to a logarithmic increase in soil losses (Figure 3).

It was also observed that conservational managements, contour tillage (CT) and no-tillage (NT) were more effectivein reducing the water and sediment loss (Table 2).
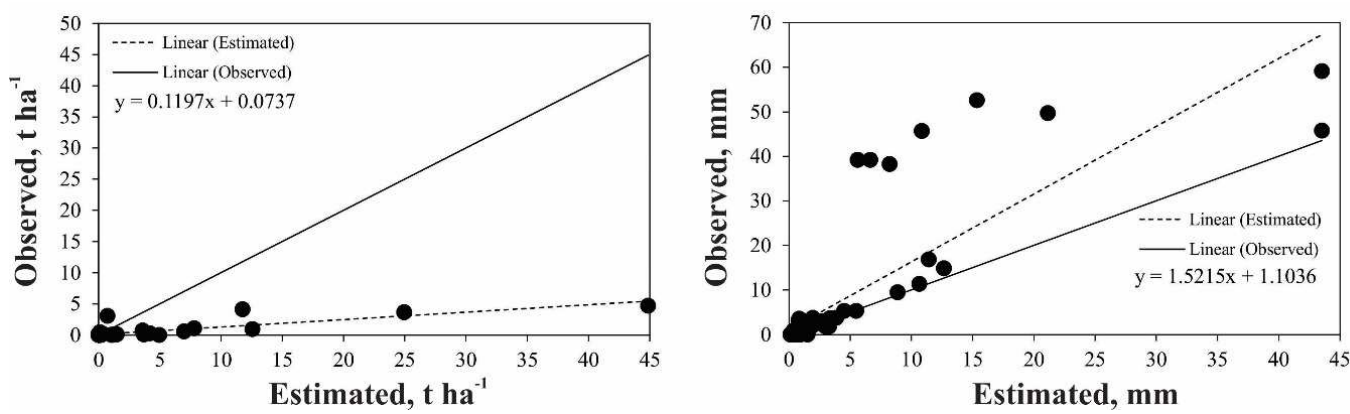

Figure 3. Relationships between observed soil and water losses in field and simulated by WEPP in different soil managemets $(n=72)$. 
On the other hand, bare soil (BS) and downhill tillage (DT) managements in general resulted in the highest loss values.

In the field experiment the grass planted had a little effect on sediment and water losses, due to a large rainfall event that occurred at the beginning of the experiment eroded great percentage of total seeds. Assessing the loss of water and sediment, the following sequence was observed among the managements: $\mathrm{BS}>\mathrm{DT}>\mathrm{CT}>$ NT (Table 2). The highest value of water losses were observed for BS and DT managements that showed $63.5 \mathrm{~mm}$ (Table 2).

The maximum soil loss $\left(44.86 \mathrm{tha}^{-1}\right)$ and the large variation $\left(6.41 \mathrm{tha}^{-1}\right)$ among losses was observed for the BS management (Table 2). Majority of P losses in the NT and CT managements were found in the runoff water. In the meantime, most of the losses of $P$ were observed in sediment for the BS and DT managements (Table 2). DT management showed highest mean of P loss (42.12 $\left.\mathrm{g} \mathrm{ha}^{-1}\right)$ and total accumulated (758.17 $\mathrm{g} \mathrm{ha}^{-1}$ ) P loss in runoff water. The most efficient management to reduce the dissolved $\mathrm{P}$ loss was the CT management (Table 2).

In terms of adsorbed P losses, BS (71.51 $\mathrm{g} \mathrm{ha}^{-1}$ ) and DT (24.95 $\mathrm{g} \mathrm{ha}^{-1}$ ) managements resulted in high $\mathrm{P}$ losses compared to other managements. While evaluating accumulated $\mathrm{P}$ in the two compartments (water and sediment), the following sequence was observed for high to low P loss: $\mathrm{BS}>\mathrm{DT}>>\mathrm{NT}>\mathrm{CT}$.

Table 2. Water, sediment and $P$ losses in different soil managements under natural rainfall $(n=18)$.

\begin{tabular}{|c|c|c|c|c|}
\hline & CT & DT & NT & BS \\
\hline \multicolumn{5}{|l|}{ Water (mm) } \\
\hline *Mean & 9.3 & 15.6 & 8.5 & 17.51 \\
\hline Maximum & 30.8 & 63.5 & 17.4 & 63.46 \\
\hline Minimum & 4.2 & 4.2 & 4.8 & 3.90 \\
\hline Stad. & 4.2 & 13.0 & 3.7 & 14.83 \\
\hline Total & 166.5 & 280.5 & 152.4 & 315.3 \\
\hline$\%$ of loss in total rain & 51.2 & 86.3 & 46.8 & 96.9 \\
\hline \multicolumn{5}{|l|}{$\mathrm{P}$ in water $\left(\mathrm{g} \mathrm{ha}^{-1}\right)$} \\
\hline${ }^{*}$ Mean & 10.36 & 42.12 & 17.66 & 28.83 \\
\hline Maximum & 45.49 & 347.99 & 143.03 & 358.22 \\
\hline Minimum & 0.39 & 0.24 & 0.16 & 0.42 \\
\hline Stad. & 9.43 & 60.26 & 24.14 & 43.61 \\
\hline Total P loss in water & 186.43 & 758.17 & 317.87 & 518.92 \\
\hline \multicolumn{5}{|l|}{ Sediment $\left(\mathrm{t} \mathrm{ha}^{-1}\right)$} \\
\hline${ }^{*}$ Mean & 0.31 & 2.17 & 0.02 & 4.84 \\
\hline Maximum & 4.18 & 24.95 & 0.24 & 44.86 \\
\hline Minimum & 0.00 & 0.00 & 0.00 & 0.00 \\
\hline Stad. & 0.52 & 3.22 & 0.04 & 6.41 \\
\hline Total & 5.71 & 39.10 & 0.45 & 87.27 \\
\hline \multicolumn{5}{|l|}{$\mathrm{P}$ in sediment $\left(\mathrm{g} \mathrm{ha}^{-1}\right)$} \\
\hline${ }^{*}$ Mean & 1.66 & 43.69 & 1.34 & 71.51 \\
\hline Maximum & 23.20 & 714.49 & 14.14 & 614.59 \\
\hline Minimum & 0.00 & 0.00 & 0.00 & 0.00 \\
\hline Stad. & 2.54 & 74.53 & 1.95 & 100.27 \\
\hline Total P loss in sediment & 29.82 & 786.51 & 24.12 & 1287.14 \\
\hline${ }^{\#}$ Total amount of P loss & 216.26 & 1544.67 & 341.99 & 1806.06 \\
\hline
\end{tabular}




\subsection{Erosion modeling}

For all soil managements, there was an overestimation of water losses based on PBAIS. The highest values of overestimation were observed for NT and CT managements with $186.18 \%$ and $136.17 \%$ respectively. The lowest PBAIS values were observed for BS and DT managements (Table 3). Overall, the WEPP model underestimated the losses of sediment, and that ranging from 78.88 to $89.08 \%$, the exception was the NT management that the model overestimated the losses in $77.41 \%$ (Table 3 and Figure 4). The RMSE coefficient was high for water losses for all the managements that ranged from 15.48 in NT management to 6.64 in DT management. For the sediment losses, RMSE values ranged from 0.08 in the NT management to 17.86 in the BS management (Table 3).

Table 3. Statistical parameters for evaluating water and sediment losses estimates by WEPP in field experiment under different soil managements.

\begin{tabular}{lrrrr}
\hline \multicolumn{1}{l}{ CT } & \multicolumn{1}{l}{ DT } & \multicolumn{1}{l}{ BS } \\
\hline Water & & & & \\
& & & & \\
RMSE & 14.37 & 6.64 & 15.48 & 14.54 \\
PBAIS & -136.17 & -33.16 & -186.18 & -63.10 \\
\hline Sediment & & & & \\
RMSE & 1.20 & 7.27 & 0.08 & 17.86 \\
PBAIS & 89.08 & 78.88 & -77.41 & 86.82 \\
\hline
\end{tabular}

RMSE: root mean square error; PBIAS: percent bias.

\subsection{Laboratory experiment}

The loss of water and sediment under simulated rainfall are given in Table 4. Under the intensity $50.3 \mathrm{~mm} \mathrm{~h}^{-1}$ the NT management was effective in avoiding the water loss by runoff. Moreover, BS management had the highest water loss $(10.33 \mathrm{~mm})$. It is noted that BS management had two times the values of water loss than DT management and almost two and half times when compared to the CT management. These results demonstrate the influence that the pasture cover and litter cover was able to reduce the water losses under low intensity of rain.

For the high rainfall intensity $\left(114.13 \mathrm{~mm} \mathrm{~h}^{-1}\right)$, the water loss in the NT management was half of that from the BS management $(53.34 \mathrm{~mm})$. When water loss from BS management was compared with CT and DT managements, it is clear that the soil management practices had lower effect in reducing the water loss with the high amount of rainfall (Table 4).

NT management was the most effective management to avoid sediment losses not being verified any loss in the two rainfall intensities studied. Also, the CT management proved to be an effective management to reduce the sediment loss. This proves that the adoption of conservation practices associated with a cover crop such as grazing can significantly reduce sediment loss. A decrease of sediment loss was $92.85 \%$ when compared the CT management with BS management in the intensity $50.3 \mathrm{~mm} \mathrm{~h}^{-1}$, and $90.90 \%$ in the intensity of $114.13 \mathrm{~mm} \mathrm{~h}^{-1}$ (Table 4). The highest values of sediment losses were associated with DT management in the intensity of $50.3 \mathrm{~mm} \mathrm{~h}^{-1}$ (Table 4). 
Table 4. Water and sediment losses in different soil managements under simulated rainfall.

\begin{tabular}{lllll}
\hline Rainfall intensities & CT & DT & NT & BS \\
\hline Water $(\mathrm{mm})$ & & & & \\
$50.3 \mathrm{~mm} \mathrm{~h}^{-1}$ & 4.15 & 4.88 & 0.00 & 10.33 \\
$114.13 \mathrm{~mm} \mathrm{~h}^{-1}$ & 43.45 & 41.97 & 28.51 & 53.34 \\
\hline \% of water loss in total rain simulated & 28.93 & 28.49 & 17.33 & 38.72 \\
\hline Sediment $\left(\mathrm{t} \mathrm{ha}^{-1}\right)$ & & & & \\
$50.3 \mathrm{~mm} \mathrm{~h}^{-1}$ & 0.03 & 0.71 & 0.00 & 0.42 \\
$114.13 \mathrm{~mm} \mathrm{~h}^{-1}$ & 0.04 & 0.10 & 0.00 & 0.44 \\
\hline
\end{tabular}

CT: contour tillage; DT: downhill tillage; NT: no-tillage; BS: bare soil.

As shown in Figure 4, the BS management was the first management to initiate runoff (12 minutes) with the rainfall intensity $50.3 \mathrm{~mm} \mathrm{~h}^{-1}$. It was observed that the sediment runoff rate was $2.91 \mathrm{~g} \mathrm{~L}^{-1} \mathrm{~min}^{-1}$ at the beginning of the runoff, and the sediment runoff rate increased along with the time till the end of the experiment. The polynomial model was the best model to describe the enrichment rate of sediment in runoff (Figure 4).

For the CT management, the runoff stated after 21 minutes after rainfall started. Nevertheless, there was low enrichment rate of sediment in runoff. For the CT management, it was observed that a small increase in the enrichment rate of sediment in runoff, reaching the rate of $1.25 \mathrm{~g} \mathrm{~L}^{-1} \mathrm{~min}^{-1}$ around 25 minutes of experiment. However, a decrease in sediment runoff was observed towards the end of the experiment (Figure 4). The model that best described this behavior was the polynomial for this management (Figure 4).

For the DT management, the runoff started after 23 minutes. The DT management showed the highest peak of sediment enrichment rate. After 26 minutes, the enrichment rate reached $81.48 \mathrm{~g} \mathrm{~L}^{-1} \mathrm{~min}^{-1}$, which was numerically the highest value, even when compared to the BS management (Figure 4). The polynomial model was the best to describe the enrichment rate of sediment in runoff for this management (Figure 4). In general, the values of coefficient of determination that described the enrichment rate of sediment in run off observed in the second simulated rain $\left(114.13 \mathrm{~mm} \mathrm{~h}^{-1}\right)$ were lowercompared to the first rain, especially for the CT mana- gement $\left(\mathrm{BS}-\mathrm{R}^{2}=0.40\right.$; $\mathrm{DT}-\mathrm{R}^{2}=0.30 ; \mathrm{CT}-\mathrm{R}^{2}$ $=0.13$ ) (Figure 4). It was observed that during the evaluation period, the enrichment rate of sediment in runoff the levels were numerically lower compared to the first simulation (Figure 4).

As can see in Figure 4 in the second simulated rain $\left(114.13 \mathrm{~mm} \mathrm{~h}^{-1}\right)$ in the BS management was observed that the runoff initiated after 3 minutes and the sediment concentration rate in the runoff was $4.61 \mathrm{~g} \mathrm{~L}^{-1}$ $\min ^{-1}$. After 15 minutes into the experiment, a small decrease of enrichment rate was observed $(3.73 \mathrm{~g}$ $\mathrm{L}^{-1} \mathrm{~min}^{-1}$ ) in this management causing a tendency to increase at the end of the experiment $\left(5.67 \mathrm{~g} \mathrm{~L}^{-1}\right.$ $\left.\min ^{-1}\right)$. The DT management also start the runoff after 3 minutes, and after 15 minutes was observed a small increase in the rate of enrichment of sediment in runoff $\left(2.83 \mathrm{~g} \mathrm{~L}^{-1} \mathrm{~min}^{-1}\right)$. Although this behavior has been observed, the trend at the end of the experiment was the decrease in enrichment rate. The polynomial model was the best to describe the enrichment rate of sediment in runoff when evaluating the BS and DT managements in the second simulated rain (114.13 $\mathrm{mm} \mathrm{h}^{-1}$ ) (Figure 4).

To the CT management the runoff started after 4 minutes. In this management in the beginning of experiment was observed higher values of the rate of enrichment of sediment in runoff with $1.3 \mathrm{~g} \mathrm{~L}^{-1} \mathrm{~min}^{-1}$, and a tendency to decrease at the end of the experiment was observed (Figure 4). The potential model was best to describe this behavior (Figure 4) 

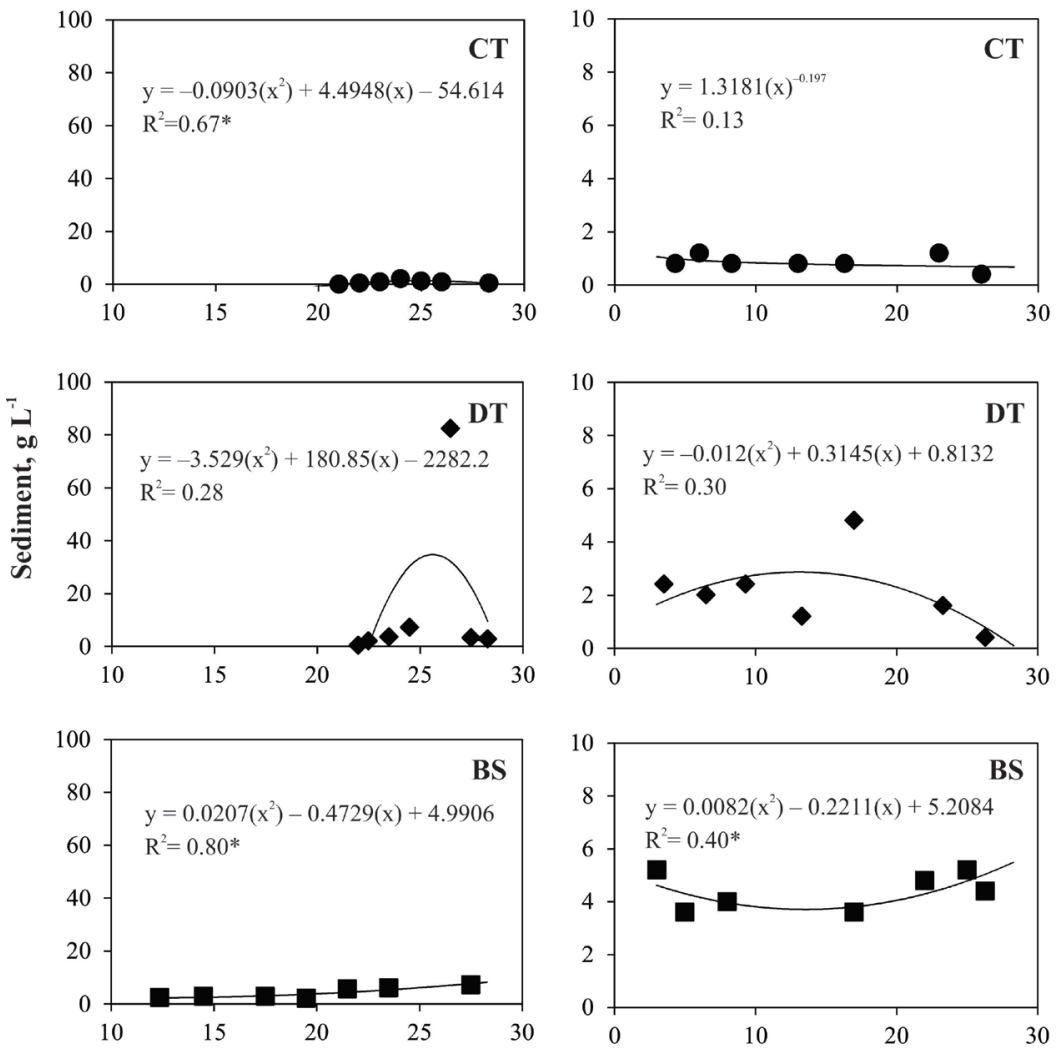

Time, minutes

Figure 4. Enrichment rate of sediment in runoff $\left(\mathrm{g} \mathrm{L}^{-1}\right)$ in 30 minutes evaluated in diferents soil managements. A- $50.3 \mathrm{~mm} \mathrm{~h}^{-1}$ and B- $114.13 \mathrm{~mm} \mathrm{~h}^{-1}$. CT-Contour tillage; DT- Downhill tillage; NT- No tillage; BS- Bare soil. * Significant differences at $p \leq 0.05$ using $F$-test and ANOVA.

\section{Discussion}

Based on the results, it was observed that in agriculture area with no-tillage, especially in regions with higher relief (32\%), the residue of the crop must be left constantly on the soil. When is not possible leave the residue on the soil, especially in areas of growing corn (Downing et al., 2011), the tillage should be done in contour. Soil preparation in up and downhill should be avoided, as well as the removal of all residues of the crops. The harvest of all crop residue or vegetation can lead to soil have a similar behavior to the bare soil (BS) management, that can increase water, sediment and P losses (Tables 2 and 4).

As observed in the field and laboratory experiments, the large rainfall events, had direct in general implications for the increase in water losses independent to the soil management. This indicated that the soil management practices have less effect on this variable when the volume of precipitated water is high. Thus, to preserve the quality of soil and water sources, it is necessary to combine these management systems, 
including the no-tillage with other conservation practices such as terraces (Hernani et al., 1999). The soil management practices seemed to influence the sediment and $\mathrm{P}$ losses, or, reducing water and $\mathrm{P}$ losses in lower rainfall events (Figure 2 and Table 2 and 4).

As seen in the laboratory experiment the association of conservational practice with cover crop such pasture it could be a good option to reduce the sediment and water losses in areas with high slope.

The highest values $(p \leq 0.05)$ of water, sediment and $\mathrm{P}$ losses in BS and DT managements may be associated with the soil exposure and lack soil cover. To the DT management, the highest values of losses may be associated with soil preparation towards the slope, which created a little physical impediment to runoff. Rows along up and down slope work as drains canals, where the runoff water can concentrate in the final slope, dissolving and carrying the soil with higher energy (Luciano et al., 2009).

The results of this study corroborates the findings in the earlier studies on NT management (Baumhardt et al., 2012). The small loss in this management can be attributed to the deposition of straw on the soil, which leads to soil protection, avoiding the direct impact of raindrops and the aggregates break (Rocha Junior et al., 2016). The reduction of the aggregates break causes a reduction of transportation of soil particles, in addition to the litter deposition hampering surface flow, thereby promoting greater water infiltration into the soil and lower runoff (Baumhardt et al., 2012).

The low values of sediment, water and $\mathrm{P}$ losses found in the CT management can be attributed to the microdepressions in the opposite direction of the slope. Preparing the soil in an opposite direction of the slope creates structures similar to micro-terrace and serves as a physical impediment to the runoff, avoiding, especially the loss of sediment (Luciano et al., 2009; Rocha Junior et al., 2016). The advantages of cultivation in contour are indicated in literature, especially after the establishment of cultures (Barbosa et al., 2010; Rocha Junior et al., 2016).

The lowest $(p>0.05)$ P loss in the NT and CT managements are related to lower values of water and sediment losses. Also, greater cumulative loss of $\mathrm{P}$ in NT management compared to the CT management, even with lower losses of water and sediments may be related to the further enrichment of this nutrient in the NT management of the surface layer as pointed out by Daniel et al. (1994) and McDowell and McGregor (1980).

The reduction of losses after the adoption of NT and CT management, and high losses values in BS and DT managements are very important to agricultural and environmental perspective, in case of changes on soil managements practices seeking for energy matrix expansion. The reduction of losses means increased water recharge in the soil, soil quality maintenance, fertilizer efficiency; reduce financial loss and no contamination of the courses with sediment (Pande et al., 2013; Pimentel et al., 1995). It also prevents erosion and transports at high levels of $\mathrm{P}$, which is an essential nutrient for plants and is a major cause of eutrophication nutrient in watercourses (Carptenter, 2008).

Corroborating the findings from the different parts of the world, it was observed that higher losses of sediment also resulted in greater loss of $\mathrm{P}$ for BS and DT managements (Anderson et al., 2011; Díaz et al., 2013). Conversely, the managements which had lower values of sediment loss (NT and CT), higher P loss was observed in the water flow. These results may be related to the high enrichment ratio of $\mathrm{P}$ (Bertol et al., 2004; Hernani et al., 1999) which, therefore, is more concentrated in eroded sediment.

The CT, DT and BS managements had the highest enrichment rate of runoff with sediment observed after the first simulation of rain, suggesting that the increase risk of sediment losses, and possible higher transport of $\mathrm{P}$ are associated to the first rainfall and the 
proximity to the tillage operations to the rainy events. Possibly this behavior is related to the power of the first rain in carry the material weakly added, and the directly impact of raindrops on the soil (Luciano et al., 2009). In addition, the $\mathrm{CT}$ and DT managements may be related to wear microrelief created after preparation.

As the DT management, preparation was performed following the slope that may have influenced to the highest enrichment peak of the runoff. High energy flow at the end of slope associated with the recently prepared soil with low aggregation may have facilitated the sediment transport.

Agreeing with the findings of Luciano et al. (2009) that found a decreased in sediment concentration in runoff over the testing, in the present study after the second intensity little increase on runoff sediment enrichment rate was observed. As the most of microdepressions which create a preferential channel for the flow of the water down the hill have been undone after the first rain simulation, the second simulation even with great intensity and volume just having little effect (Rocha Junior et al., 2016).

Modeling results indicated that more variables related to soil and management practices, especially adopted prior to the establishment of the current management should be taken into account when estimating losses of sediment and water using the WEPP. The lack of information about initial saturation level, critical shear, interrrill and rill erodibility, soil roughness and others difficult the modeling. Although the WEPP programs simulates these variables base on soil attributes, and recommend values based on several soil analyses, the better option is collect these variables in the field for a better simulation result.

The WEPP model results showed similar behavior in losses, but the values had different magnitude (Figure 3). For different management the PBAIS values showed under-overestimation of data, and were highhigher than range established by Moriasi et al. (2007) $\pm 55 \%$ to consider a model to be satisfactory. It indicated that the model simulation demonstrated low degree of accuracy. The values of RMSE far from zero (except for NT in sediment) indicated that there was not a good agreement between observed and estimated data (Moriasi et al., 2007), indicating that is necessary to conduct more studies to improve the accuracy of WEPP in hilly areas.

\section{Conclusions}

Based on the field and laboratory experiments, it was observed that soil management practices had little effect on water loss in rainfall with high intensity. This indicated that more studies need to be conducted to look for alternatives focused on mitigate options to reduce water losses in agricultural areas with high slopes. The greatest influence of soil management was related to reduced sediment and $\mathrm{P}$ losses, or reduced water and $\mathrm{P}$ losses in rains with low amount. The WEPP model generally overestimated the losses of water and underestimated the sediment losses for the four management studied. The most recommended practice in the areas with high slope is the no-tillage, due to observed lower water and sediment losses. In case no-till is not feasible for some reason, the contour tillage is another beneficial practice for soil and water conservation. The total removal of cover and soil preparation along the slope should be avoided. Soil management practices have a direct effect on the enrichment rate of runoff with sediment. The first rainfall and the proximity to the rainfall with soil management practices are the factors that have more influence to increase the rate of enrichment runoff with sediment. In general the sequence of soil and water losses observed in the different soil managements was: $\mathrm{BS}>\mathrm{DT}>\mathrm{CT}>\mathrm{NT}$. 


\section{Acknowledgements}

The authors are grateful to the Research Support Foundation of the Espírito Santo State (FAPES, State government) for the financial support, CAPES - Coordenação de Aperfeiçoamento de Pessoal de Nível Superior (PDSE) and CNPQ - Conselho Nacional de Desenvolvimento Científico e Tecnológico (grant PDE 248906/2013-5) for the scholarships, and to the University of Illinois for the technical support

\section{References}

Arnold, J.G., Srinivasan, R., Muttiah, R.S., Williams, J.R. 1998. Large area hydrologic modeling and assessment: Part I. Model development. Journal of the American Water Resources Association. 34, 73-89.

Anderson, G., Bell, R., Brennan, R., Chen, W. 2011. Soil management calculator for predicting phosphorus losses under cropping systems in Western Australia. Agribusiness Crop Updates. 2011, 41-45.

Barbosa, F.T., Bertol, I., Vieira Luciano, R., Paz-Ferreiro, J. 2010. Sediment size and organic carbon content in runoff and soil under two crops and two seed row directions. Revista Brasileira de Ciência do Solo. 34, 1701-1710.

Baumhardt, R.L., Johnson, G.L., Schwartz, R.C. 2012. Residue and long-term tillage and crop rotation effects on rain infiltration and sediment transport. Soil Science Society of America Journal. 76, 1370-1378.

Beniston, J.W., Shipitalo, M.J., Lal, R., Dayton, E.A., Hopkins, D.W., Jones, F., Joynes, A., Dungait, J.A.J. 2015. Carbon and macronutrient losses during accelerated erosion under different tillage and residue management. European Journal of Soil Science. 66, 218-225.

Bertol, I., Guadagnin, J.C., Cassol, P.C., Amaral, A.J., Barbosa, F.T. 2004. Phosphorus and potassium losses by water erosion in an inceptisol under natural rainfall. Revista Brasileira de Ciência do Solo. 28, 485-494.

Bhattarai, R., Kalita, P.K., Yatsu, S., Howard, H.R., Svedsen, N.G. 2011. Evaluation of compost blankets for erosion control from disturbed lands. Journal Environment Management. 92, 803-812.

Carptenter, S.R. 2008. Eutrophication control is critical to mitigating eutrophication. Proceedings of the National Academy of Science of the United States of America. 105, 11039-11040.

Daniel, T.C., Sharpley, A.N., Edwards, D.R., Wedepohl, R., Lemunyon, J.L. 1994. Minimizing surface water eutrophication from agriculture by phosphorus management. Journal of Soil and Water Conservation. 49, 30-38.

Díaz, I., Del Campillo, M.C., Barrón, V., Torrent, J., Delgado, A. 2013. Phosphorus losses from two representative small catchments in the Mediterranean part of Spain. Journal of Soils and Sediments. 13, 1369-1377.

Drewniak, B.A., Mishra, U., Song, J., Prell, J., Kotamarthi, V.R. 2015. Modelling the impact of agricultural land use and management on US carbon budgets. Biogeosciences. 12, 2119-2129.

Downing, M., Eaton, L.M., Graham, R.L., Langholtz, M.H., Perlack, R.D., Turhollow Jr, A.F., Stokes, B., Brandt, C.C. 2011. U.S. billion-ton update: Biomass supply for a bioenergy and bioproducts industry, U.S. Dep. of Energy, Washington, DC.

EISA -Summary of the Energy Independence and Security Act., Public Law 110-140, 2007. https:// www.epa.gov/laws-regulations/summary-energyindependence-and-security-act

Flaganan, D.C., Livingston, S.J. 1995. NSREL Report No.11. USDA-ARS National Soil Erosion Res. Lab, West Lafayette, IN.

Ferreira, D.F. 2011. Sisvar: A computer statistical analysis system. Ciência e Agrotecnologia. 35, 1039-1042. 
Hernani, L.C., Kurihara, C.H., Silva, W.M. 1999. Sistemas de manejo do solo e perdas de nutrientes e matéria orgânica por erosão. Revista Brasileira de Ciência do Solo. 23, 145-154.

Horowitz, J.R., Ebel, R., Ueda, K. 2010. No-till farming is a growing practice, Economic Information Bulletin No. 70. USDA-ERS, Washington, DC.

Jarvie, H.P., Sharpley, A.N., Withers, P.J.A., Scott, J.T., Haggard, B.E., Neal, C. 2013. Phosphorus Mitigation to Control River Eutrophication: Murky Waters, Inconvenient Truths, and "Postnormal" Science. Journal of Environmental Quality. 42, 295-304.

Lynd, L.R., Laser, M.S., Bransby, D., Dale, B.E., Davidson, B., Hamilton, R., Himmel, M., Keller, M., McMillan, J.D., Sheehan, J., Wyman, C.E. 2008. How biotech can transform biofuels. Nature Biotechnology. 26, 169-172.

Luciano, R.V., Bertol, I., Barbosa, F.T., Vázquez, E.V., Fabian, E.L. 2009. Water and soil losses through water erosion under oat and vetch sown in two directions. Revista Brasileira de Ciência do Solo. 33, 669-676.

McDowell, L.L. McGregor, K.C. 1980. Nitrogen and phosphorus losses in runoff from no-till soybeans. Transactions of ASAE. 23, 643-648.

Moriasi, D.N., Arnold, J.G., Van Liew, M.W., Binger, R.L., Harmel, R.D., Veith, T. 2007. Model evaluation guidelines for systematic quantification of accuracy in watershed simulations. Transactions of ASAE. 50, 885-900.

Nearing, M.A., Lane, L.J., Lopes, V.L. 1994. Modeling Soil Erosion. LAL, R. (Ed.) Soil erosion: research methods. Delray Beach: St. Lucie Press. p. 127-135.

Pande, V.C., Kurothe, R.S., Singh, H.B., Tiwari, S.P., Kumar, G. 2013. Economic Assessment of Soil Erosion Damage on Smallholder Farms in Mar- ginal Lands of Mahi Ravines in Gujarat. Agricultural Economics Research Review. 26, 63-71.

Perlack, R.D., Wright, L.L., Turhollow, A.F., Graham,R.L., Stokes, B.J., Erbach, D.C. 2005. Biomass as feedstock for a bioenergy and bioproducts industry: the technical feasibility of a billion-ton annual supply. U.S. Department of agriculture. 1-59.

Pimentel, D., Harvey, C., Resosudarmo, P., Sinclair, K., Kurz, D., McNair, M., Crist, S., Shpritz, L., Fitton, L., Saffouri, R., Blair, R. 1995. Environmental and economic costs of soil erosion and conservation benefits. Science. 267, 1117-1123.

Rocha Junior, P.R., Bhattarai, R., Alves, R.B.F., Kalita, P.K., Andrade, F.V. 2016. Soil surface roughness under tillage practices and its consequences for water and sediment losses. Journal of Soil Science and Plant Nutrition. 16, 1065-1074.

Shen, Z.Y., Gong, Y.W., Li, Y.H., Liu, R.M. 2010. Analysis and modeling of soil conservation measures in the Three Gorges Reservoir Area in China. Catena. 81, 104-112.

USDA - Soil Survey Staff. Web Soil Survey, Natural Resources Conservation Service, USDA, 2013. http://websoilsurvey.nrcs.usda.gov.

USEPA, Method 365.2. Phosphorus, All Forms (Colorimetric, Ascorbic, Acid, Single Reagent). United States Environmental Protection Agency, Washington, D.C., 1971. (EPA 600/4-79020) Available at: https://www.epa.gov/sites/ production/files/2015-08/documents/method_365-3_1978.pdf

Wei, W., Chen, L., Fu, B., Chen, J. 2010. Water erosion response to rainfall and land use in different drought-level years in a loess hilly area of China. Catena. 81, 24-31. 


\subsubsection{Data collection}

The loss of water was measured after each rainfall event using graduated buckets to measure the amount of water lost, and the water samples were collected for analysis of P. For determining the loss of sediment, all remaining material in the gutters and supernatants inside the boxes were collected. The sediment was air dried and weighed. Water samples were filtered $(0.7 \mu \mathrm{m})$, and were analyzed to determine $\mathrm{P}$ contents by colorimetric method using automated ascorbic acid reduction. Sediment samples of $0.5 \mathrm{~g}$ were digested using a mixture of concentrated sulfuric acid $(4 \mathrm{~mL})$ and 2.1.3. Modeling sediment and water losses by WEPP

In order to model the sediment and water losses at the field experiment, the Water Erosion Predict Project (WEPP) (Nearing et al., 1994) program was used. Input data for the model such as climate, length and steepness of slope, soil and management were collected during the field experiment. Climate data were collected with a weather station located in the experi- mental farm near the experimental site. Isolated rain was studied using the function single storms, added data of storm amount ( $\mathrm{mm}$ ), storm duration (h), maximum intensity $\left(\mathrm{mm} \mathrm{h}^{-1}\right)$ and duration to peak intensity (\%). Lengths (m) and ramp slopes (\%) were taken from the section plots preparation and soil managements.

The input data regarding the soil used was from Table 1 , and as the values of interrill erodibility, rill erodibility and critical shear was not available, these variables were calculated on base of soil physical attributes, using the "have model calculate" tool. For the initial saturation level, $70 \%$ of initial level saturation, which is about $33 \mathrm{kPa}$ (field capacity) for most soils was used ase per recommended for WEPP program. Other input information collected during the experiments were bulk density after the last tillage $\left(1.1 \mathrm{~g} \mathrm{~cm}^{-3}\right)$, initial canopy cover $(0 \%)$, days after the last tillage (200 d), cumulative rainfall since last tillage (500.1 $\mathrm{mm})$, initial ridge height after last tillage $(2 \mathrm{~cm})$, and initial roughness after last tillage $(2 \mathrm{~cm})$.

\subsection{Laboratory experiments}

\subsubsection{Soil chambers preparation and soil managements}

The lab experiment was conducted under a rainfall simulator at the Agricultural and Biological Engineering Department at the University of Illinois. Two horizontal tilting soil chambers were used to investigate soil erosion patterns from soil under different managements. The chambers contained $3.60 \mathrm{~m}$ of ramp length and $1.50 \mathrm{~m}$ of width. The chambers were filled with similar soil to the field experiment; the unique difference was the SOC content (2.5\%). More details about the soil chamber and soil accommodation see Bhattarai et al. (2011) (Table 1). 